\title{
Assessment of Intratumoral Heterogeneity in Isolated Human Primary High-Grade Glioma: Cluster of Differentiation 133 and Cluster of Differentiation 15 Double Staining of Glioblastoma Subpopulations
}

\author{
Ahmad Faried ${ }^{1 *}$, Wahyu Widowati ${ }^{2}$, Rizal Rizal ${ }^{3}$, Hendrikus M.B. Bolly ${ }^{4}$, Danny Halim ${ }^{1}$, Wahyu S. Widodo ${ }^{3}$, Satrio H.B. Wibowo ${ }^{3}$, \\ Rachmawati Noverina ${ }^{5}$, Firman P. Tjahjono ${ }^{1}$, Muhammad Z. Arifin ${ }^{1}$ \\ ${ }^{1}$ Department of Neurosurgery, Faculty of Medicine, Universitas Padjadjaran, Dr. Hasan Sadikin Hospital, Bandung, West Java, \\ Indonesia; ${ }^{2}$ Medical Research Center, Faculty of Medicine, Maranatha Christian University, Bandung, West Java, Indonesia; \\ ${ }^{3}$ Biomolecular and Biomedicine Research Center, Aretha Medika Utama, Bandung, West Java, Indonesia; ${ }^{4}$ Department of \\ Biochemistry, Faculty of Medicine, Cenderawasih University, Papua, Indonesia; ${ }^{5}$ PT. Bio Farma (Persero), Bandung, West \\ Java, Indonesia
}

Edited by: Ksenija Bogoeva-Kostovska
Faried A, Widowati W, Rizal R, Bolly HMB Citation: Faried A, Widowati W, Rizal R, Bolly HMB, Tjahjono FP, Arifin MZ. Assessment of Intratumora Heterogeneity in Isolated Human Primary High-Grade Glioma: Cluster of Differentiation 133 and Cluster of Differentiation 15 Double Staining of Glioblastom ubpopulations. Open Access Maced J Med Sci. 202 Jan 04; 9(A):87-94 https://doi.org/10.3889/oamjms.2021.551 Keywords: Glioblastoma; Glioma stem cells; Subpopulations; Cluster of differentiation 133; Cluster of differentiation 15 Correspondence: Anmad Fedicine, Depiversitas Padjadjaran-Dr. Hasan Sadikin Hospital, Jl. Pasteur No. 38, Bandung 40161, West Java, Indonesia. E-mail: faried.fkup@gmail.com Received: 17-Oct-2020 Revised: 23-Dec-2020 Accepted: 28-Dec-2020
Copyright: $\odot 2021$ Ahmad Faried, Wahyu Widowat Rizal Rizal, Hendrikus M.B. Bolly, Danny Halim, Rachmawati Noverina, Firman P. Tjahjono, Muhammad Z. Arifi

Funding: A. Faried supported by the Grants-in-Aid from Universitas Padjadjaran, West Java, Indonesia Competing Interest: The authors have declared that no competing interest exists Open Access: This is an open-access article distribute under the terms of the Creative Commons Attribution-

\begin{abstract}
BACKGROUND: Gliomas are the most common primary brain tumors, representing $50-60 \%$ of malignant primary brain tumors. Gliomas are highly heterogeneous with marked inter- and intratumoral diversity. Gliomas heterogeneity is a challenging issue in the development of personalized treatment. The simplest method for studying heterogeneity is using ex vivo cell cultures; in our case, the cell lines were isolated from patient with glioblastomas.

AIM: Here, we reported distinct cell subpopulations heterogeneity in glioblastoma cells.

METHODS: Human glioblastoma cells isolation is conducted by enzymatic method with combination of collagenase I, hyaluronidase, and trypsin enzyme in proportional amount from patient. Immunostaining was performed to assess glial fibrillary acidic protein (GFAP), Ki-67, isocitrate dehydrogenase-1 (IDH-1) status, and program death ligand-1 (PD-L1) expression. Primary glioblastoma cell line was characterized by flow cytometry (fluorescence-activated cell sorting) analysis based on cluster of differentiation (CD) 133 and CD15 marker expression. U87MG and CGNH-89 cell lines were used as control. Distinct subpopulation analysis was performed by double staining of CD133 and CD15 in isolated primary glioblastoma cell line and its comparative control cells.

RESULTS: Our isolated glioblastoma cells morphology was adherent cells which were able to form spheres depending on environment. Immunostaining confirmed GFAP, Ki-67, IDH-1 mutants, and PD-L1 expression. Our isolated glioblastoma cells expressed CD133 and CD15, coexpressed CD133/CD15 in different patterns. The highest subpopulation in primary glioblastoma was $\mathrm{CD} 133^{+} / \mathrm{CD} 15^{+}$

CONCLUSION: Glioblastoma cells can be isolated using enzymatic methods. Isolated glioblastoma cells consist of four different subpopulations distinguished by CD133/CD15 double staining. Intratumoral heterogeneity exists and directly or indirectly depends on their microenvironment.
\end{abstract}

\section{Introduction}

In adults, gliomas account for $29 \%$ of all brain tumors; $80 \%$ of primary malignant brain tumors occurring in patients $65-84$ years of age [1]. Gliomas are highly heterogeneous, infiltrative, and diffuse with different degrees of invasiveness [2]. Based on the World Health Organization (WHO) classification 2016, the glioma is divided into two subtypes: (1) Noninfiltrative and (2) infiltrative (diffuse). Diffuse types must be enforced using biomolecular parameters.

Some cancers have been reported to have a small cell population of growth sustaining and tumorigenic abilities. Such cells, known as cancer stem cells (CSCs) or cancer initiating cells, have been identified in certain kinds of tumors including gliomas [3], [4]. Intratumoral heterogeneity originated from genetic, epigenetic, and niche in addition to environmental effects and produced marked diversity within cancer cell populations. Gliomas heterogeneity is a challenging issue in the development of personalized treatment strategies. Even within cluster of glioma cells, there is a different of phenotypical and morphological states, as reflected by differences in gene expression, motility, metabolism, proliferation, metastatic potential, and drug resistance ability.

Cluster of differentiation (CD)-15 or trisaccharide 3-fucosyl- $\mathrm{N}$-acetyllactosamine, known as 
stage-specific embryonic antigen 1 (SSEA1), is strongly expressed in many types of pluripotent stem cells and neural stem cells (NSCs) in the adult brain [5]. CD15 was recently proposed to be a CSC marker derived from brain tumors [5]. CD133, which was originally detected in neuroepithelial stem cells of mice, is a cell surface marker expressed on human NSCs [3], [4], hematopoietic stem cells, and endothelial progenitor cells [6]. It is most frequently used as a representative CSC marker, in many cancers including gliomas [5].

The tumor spheres studied here indicated the existence of $\mathrm{CD}_{133^{-}}$and $\mathrm{CD} 15^{-}$glioma stem cells (GSCs), indicating that all these cells were immature. The data could imply intrinsic relationships between NSCs and GSCs, suggested that GSCs might retain some NSCs characteristics [7]. However, since normal tissue stem cells and CSCs could have some similar properties, further studies should focus on the differences, including the molecular genetics and epigenetics, between CD133 ${ }^{+}$ and/or CD15 ${ }^{+}$normal tissue stem cells and CD133 ${ }^{+}$and $/$ or CD15 ${ }^{+}$GSCs. Understanding such differences may help to elucidate the tumorigenesis and establishment of novel therapies for glioblastoma.

CD133 and CD15 were chosen since CD133 may not detectable in fresh glioblastomas specimens, meanwhile, CD15 expressed in cells with tumor initiation capacity; in glioblastomas, CD15 is an enrichment marker of stem cells in CD133-negative tumors (CD15 ${ }^{+}$cells from CD133- tumors able to form neurospheres colonies and highly tumorigenic in vivo). Double staining of CD133 and CD15 could define cell subpopulations in human primary high-grade glioma (HGG). In the current study, we isolated glioma cells from a patient and expanded the cells with spheres culture, finally, the cells were characterized by the CD133/CD15 using flow cytometry and compared to malignant gliomas U87MG cells and CGNH-89 cells [8].

\section{Materials and Methods}

\section{medium \\ Preparation of human glioblastoma cell}

\section{Transport medium}

A medium for transporting clinical specimens to the laboratory for examination, we used transport medium cocktail that based on phosphate-buffered saline (PBS) 1 (Gibco, 1740576), 1\% antibioticantimycotic (Ab-Am) (Gibco, 1772653), 1\% amphotericin B (Amp B) (Gibco, 15290026), 1\% gentamicin (Gibco, 15750060), Nanomycopulitine (Gibco, LX16010).

\section{Glioma medium (CGNH sphere, isolated HGG)}

BrainPhys Neuronal Medium (Stem Cell Technology, 05796) supplemented 5\% fetal bovine serum (FBS) (Gibco, 10270106), $20 \mathrm{ug} / \mathrm{ml}$ recombinant human epidermal growth factor (EGF) (BioLegend, 585508), $20 \mathrm{ug} / \mathrm{ml}$ recombinant human b-FGF (BioLegend, 571508), $20 \mathrm{ug} / \mathrm{ml}$ recombinant human LIF (593906), 2\% N2 (Stem Cell Technology, 07152), 2\% Neurocult (Stem Cell Technology, 05711), 1 ug/ $\mathrm{ml}$ heparin (Stem Cell Tech., 07980), 1\% Ab-Am (Gibco, 1772653), 1\% Amp B (Gibco, 15290026), $0.1 \%$ gentamicin (Gibco, 15750060), and 1\% Nanomycopulitine (Gibco, LX16010).

\section{CGNH attached and U87 medium}

The complete growth medium used to expand CGNH and U87MG cells were RPMI 1640 Medium (Biowest, L0500-500), 10\% FBS (Biowest, S1810-500), 1\% Ab-Am (Gibco, 1772653), 1\% Amp B (Biowest), 1\% gentamicin (Gibco, 15750060), and Nanomycopulitine (Gibco, LX16010).

\section{Tissue sample preparation for Ex vivo} study

The tissue sample was from a male patient, 47 years old, with HGG (WHO grade IV) malignant brain tumor. The informed consent used the guidelines approved by the Institutional Ethics Committee, Faculty of Medicine, Universitas Padjadjaran - Dr. Hasan Sadikin Hospital, Bandung, Indonesia. Tissue was then washed using PBS $1 \times$ (Gibco 1740576), then was placed in transport medium and transferred to the laboratory to be processed immediately.

\section{Immunohistochemical staining for in vitro glial fibrillary acidic protein (GFAP), Ki-67, isocitrate dehydrogenase-1 (IDH-1) mutant, and program death ligand-1 (PD-L1) study}

Resected specimens were fixed with $10 \%$ natural buffer formalin and embedded in a paraffin block. Immunostaining of the section for GFAP, Ki-67, IDH-1 $\mathrm{R} 132 \mathrm{H}$ (arginine 132 into histidine) mutant, and PD-L1 was performed using the streptavidin-biotin method. Sections (4 $\mu \mathrm{m}$ thick) were deparaffinized with xylene, rehydrated, and incubated with fresh $0.3 \%$ hydrogen peroxide in methanol for $30 \mathrm{~min}$ at room temperature. After rehydration through a graded ethanol series, the specimen was washed in PBS. After a blocking treatment with $5 \%$ skimmed milk for $30 \mathrm{~min}$, the specimens were then incubated with the anti-GFAP polyclonal antibody (SKU 040 Biocare), anti-Ki-67 monoclonal antibody (MIB-1, SKU 325 Biocare; Clone Sp6), anti-IDH-1 R132H mutant monoclonal antibody (sc-373816 Santa Cruz), and anti-PD-L1 monoclonal antibody (Ab 205921 Abcam; Clone 28-8) at a dilution of 1:100, 1:100, 1:200, and 1:200, respectively, in PBS containing $1 \%$ bovine serum albumin at $4^{\circ} \mathrm{C}$ overnight. They were then washed with PBS and incubated in secondary antibody for $30 \mathrm{~min}$ at room 
temperature. Staining was performed using a Histofine SAB-PO (M) kit (Nichirei, Tokyo, Japan). The chromogen was a $3.3-0.02 \%$ solution containing $0.0055 \% \mathrm{H}_{2} \mathrm{O}_{2}$ in a $50 \mathrm{mM}$ ammonium acetate-citric acid buffer, $\mathrm{pH}$ 6.0. The specimens were lightly counterstained with hematoxylin. Negative controls were prepared by substituting normal mouse serum for each primary antibody, as no detectable staining was evident. Each of IHC expression calculated as percentage of cytoplasmic and membranous staining of the cells at the central layer of cell layers of cancer cell nest in three consecutive high-power fields. For $\mathrm{IDH}-1, \mathrm{R} 132 \mathrm{H}$ mutant if stained was negative or $<10 \%$ categorized as negative and if $>10 \%$ as positive. PD-L1 $\mathrm{IHC}$ results were defined on the tumor proportion score as follows based on distributions as 0 (negative), 1 (<20\%), 2 (20-50\%), 3 (50-80\%), 4 (>80\%); score for intensity as 0 (negative), 1 (weak), 2 (moderate), and 3 (strong); results from distribution $\mathrm{x}$ intensity as histoscore low (0-4), moderate (4-6), and high (6-12).

\section{Ex vivo primary glioblastoma cells isolation and characterization}

The tumor tissue was washed with PBS $1 \times$ on a Petri dish and then was cut it into small pieces using surgical scalpel. The sample fragments were washed again with PBS 1× (Gibco, 1740576), inserted into $50 \mathrm{ml}$ falcon tube (TPP, 91050) containing the mixed enzyme solution of $4 \mathrm{mg} / \mathrm{ml}$ collagenase Type I (Gibco, 10114532), $1 \mathrm{mg} / \mathrm{ml}$ hyaluronidase (Sigma, 515397), trypsin 0.1\%, and then rocked $5 \mathrm{~h}, 300 \mathrm{rpm}, 37^{\circ} \mathrm{C}, 5 \% \mathrm{CO}_{2}$ followed with $16 \mathrm{~h}$ incubation, $37^{\circ} \mathrm{C}, 5 \% \mathrm{CO}_{2}$. Sample was filtered by $70 \mu \mathrm{m}$ cell strainer (Corning, 431752) then centrifuged at $1600 \mathrm{rpm}$ for $10 \mathrm{~min}$. Supernatant was discarded, the pellet was washed with PBS $1 \times$ and centrifuged at 1600 rpm 5 min $2 \times$. The pellet was then resuspended with the complete growth medium. The cell suspension was next incubated at $37^{\circ} \mathrm{C}, 5 \% \mathrm{CO}_{2}$ [9]. Glioma cells at passage 3, CGNH-89, and U87 cell line (ATCC ${ }^{\circledR}$ HTB-14 ${ }^{\mathrm{TM}}$ ) were characterized using flow cytometry (Macsquant Analyzer 10) for positive and negative markers of glioblastoma cells at density $1 \times 10^{5}$ cells/tube. The cells were then stained with PerCP/Cyanine5.5 anti-human CD15 (SSEA-1) antibody (BioLegend, 323020) and APC antihuman CD133 antibody (BioLegend, 372806) according to the manufacturer protocol. The experiments and surface marker measurements were performed in triplicate [10], [11].

\section{Ex vivo proliferation assay}

Glioma cells were cultured in glioblastoma growth medium; the medium was replaced every 3 days. $3 \times 10^{5}$ cells were seeded on T25 flask and cultured in complete medium until reaching confluence $80 \%$ around 3 days for proliferation assay. Briefly, cultured cells were detached using trypsin (Gibco, 25200072), then incubated for 1-3 min at $37^{\circ} \mathrm{C}$, complete medium was added to neutralize trypsin and the detached cells were centrifuged (MPW2000) at $1600 \mathrm{rpm}$ for $5 \mathrm{~min}$ at room temperature. The cell pellet was resuspended with trypan blue (Sigma, 25200072) and diluted in 1:1 dilution. Then, cells were counted using a hemocytometer (Neubauer, 17849). Population doubling (PD) was counted at every passage with the formula: $P D=\left[\log _{10}(\mathrm{NH})-\log _{10}(\mathrm{NI})\right] / \log 10$

$\mathrm{NI}$ is the inoculum cell number and $\mathrm{NH}$ is the cell harvest number. The cumulative PD index for each passage was obtained by adding the PD of each passage to the $P D$ of the previous passages. The $P D$ time (PDT) was determined by the formula: $P D$ time $=t$ (time)/PD (in days) [8].

\section{Data analysis}

Statistical analysis was performed using the Stat View (ver. 5.0, SAS Institute Inc., NC). Statistically significance was considered at $p<0.05$.

\section{Results}

\section{Morphological characteristics of ex vivo isolated primary HGG cells}

The glioma cells were isolated from resected brain tumor of patient with HGG; the cells were isolated by enzymatic method as described previously. The tissues cells, separation of cells, and adherent morphological characteristic are shown in Figure 1a-c. The cells showed neurosphere- like formation (Figure 1d); clonal formation of neurospheres in EGF proved that our isolated cells are likely a cancer forming cells (CSCs) [10].

\section{PD time assay, characteristics of U87 and CGNH-89 cells}

PDT assay was used to evaluate the proliferation capacity of isolated glioblastoma cells. As shown in Figure 1e, the PDT of isolated cells decreased by increasing of the cell passages. The PDT of isolated HGG in Passage 3 was 5.14 days compared to Passage 5 that has lower PDT, 3.35 days. Morphological characteristic of adherent gliomas U87MG cells shown in Figure 1f, adherent CGNH-89 cells shown in Figure $1 \mathrm{~g}$, and spheres $\mathrm{CGNH}-89$ cells shown in Figure $1 \mathrm{~h}$.

\section{In vitro immunohistochemical analysis of glioma tissue}

IHC analysis confirmed the expression of GFAP, Ki-67, IDH-1 R132H mutant, and PD-L1 in HGG (Figure $2 a-d$ ). GFAP was expressed in $>80 \%$ cells; GFAP expression showed that the glioblastoma is originated from glial cells. Ki-67 expressed in $>10 \%$ cells confirmed 

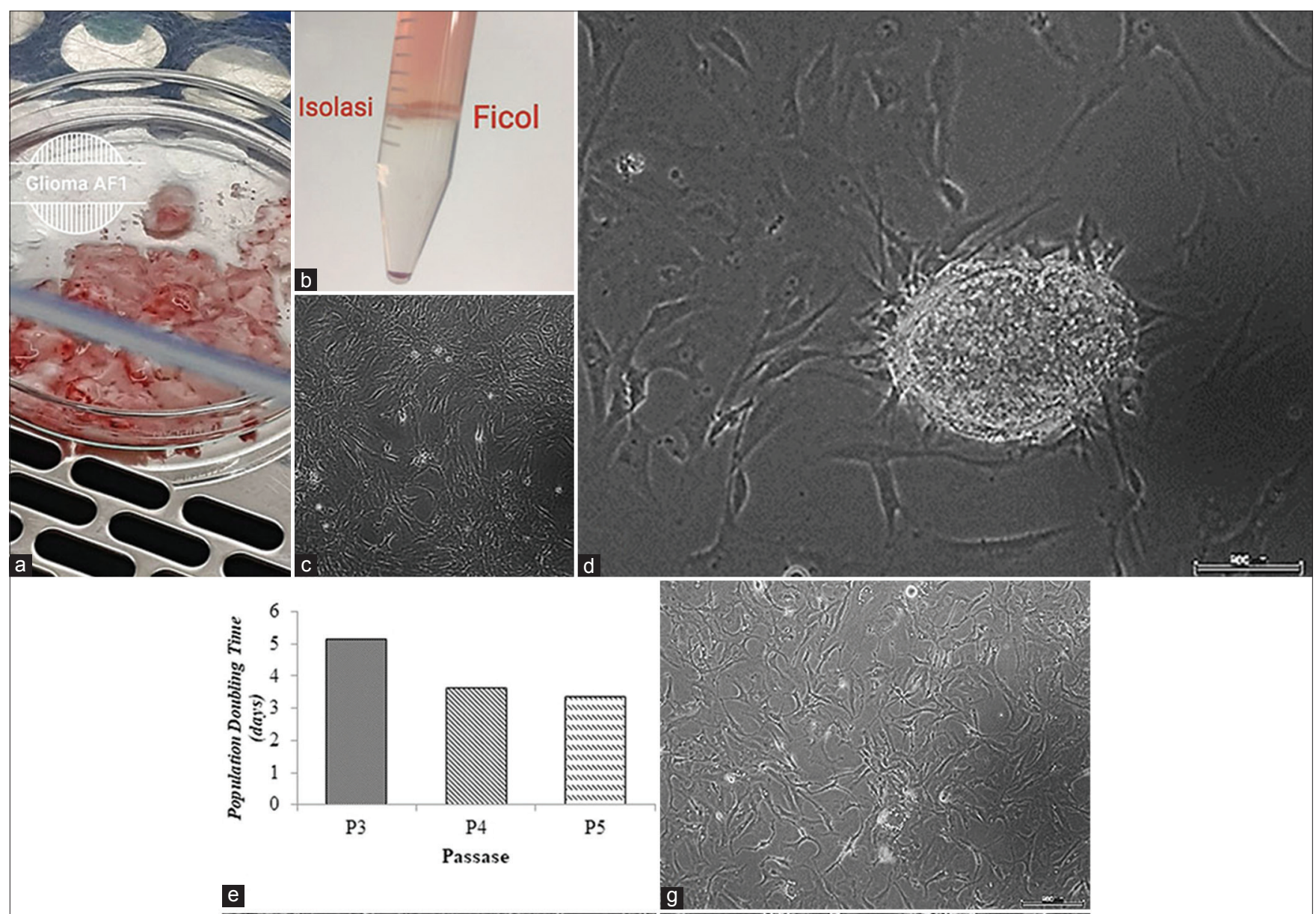

e

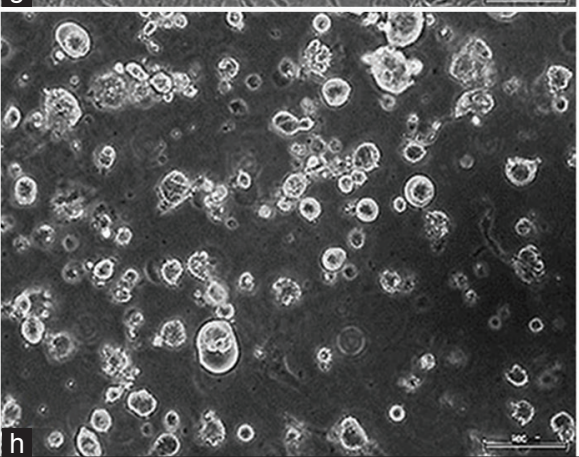

Figure 1: The isolated primary glioblastoma tissues (a), process for primary glioblastoma isolation (b), and adherent morphological characteristic (c). The isolated primary high-grade glioma glioblastoma shown as stem cells sphere morphology (d); with population doubling time count in days for primary glioblastoma cells (e). Adherent morphology of U87MG cells (f), adherent morphology of CGNH-89 cells (g), and spheres morphology of CGNH-89 cells (h)

the proliferation activity of isolated tumor since it is an important marker for proliferation in clinical practice [12]. Expression of IDH-1 R132H mutant confirmed that the tumor is likely a secondary, transformed from lower grade tumor. PD-L1 was expressed in high amount, $>80 \%$ area of the tumor. Its expression was closely correlated to the pathological grade of the glioma which was confirmed the HGG of isolated tumor [13].

\section{Characteristics of ex vivo isolated primary human HGG cells}

Flow cytometric analysis was conducted to define the biological properties of glioma cells using CD133 and CD15 markers compared to U87MG and CGNH-89 cells.
CD133 is the marker for GSCs. CD15 is the marker for neural precursor and some immature astrocytes (NSCs). All cells expressed putative GSCs CD133 (65.73 $\pm 1.12 \%$ for isolated primary HGG, 76.19 $\pm 1.42 \%$ for U87MG cells, $62.52 \pm 1.71 \%$ for adherent $\mathrm{CGNH}-89$, and $77.69 \pm 0.44 \%$ for sphere CGNH-89) and NSCs CD15 (33.56 $\pm 1.92 \%$ for isolated primary HGG, $22.52 \pm 0.34$ for U87MG cell, 22.14 $\pm 0.65 \%$ for adherent CGNH-89, and $51.17 \pm 0.54 \%$ for spheres CGNH-89) (Figure 3).

\section{Subpopulation of ex vivo isolated human} primary HGG and control cells

Double staining was performed to examine coexpression of CD133 and CD15 in isolated primary 


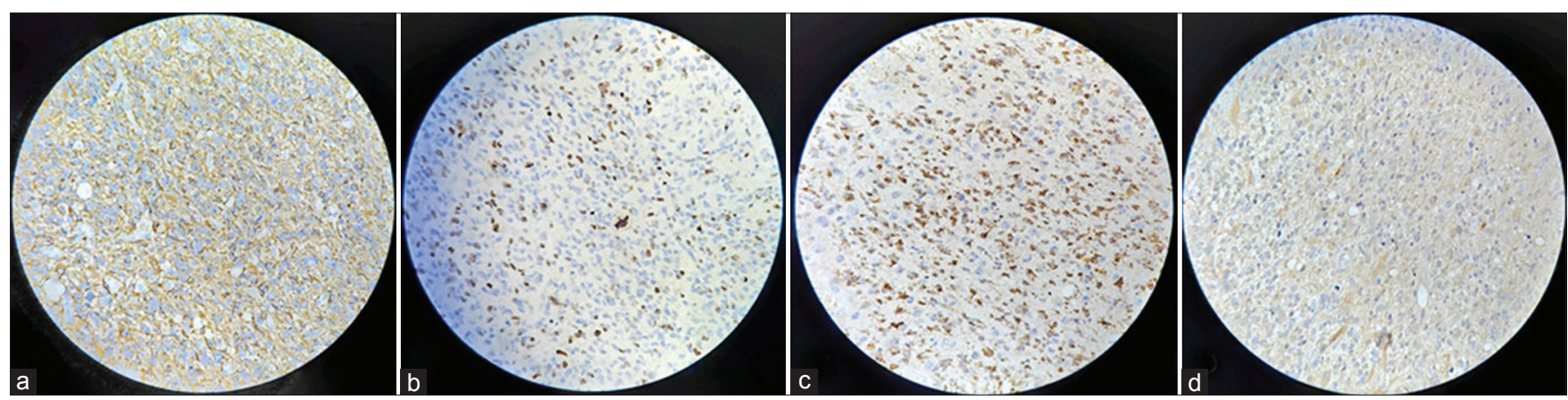

Figure 2: Immunoprofile of glioblastoma tissue. The tissues were positively stained with glial fibrillary acidic protein (a), Ki-67 (b), isocitrate dehydrogenase-1 mutants (RI32) (c), and program death ligand-1 antibody (d) (20×x).
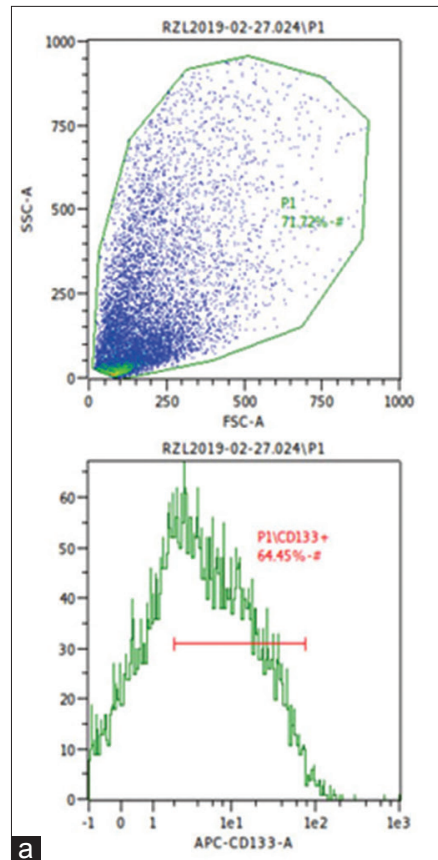

a
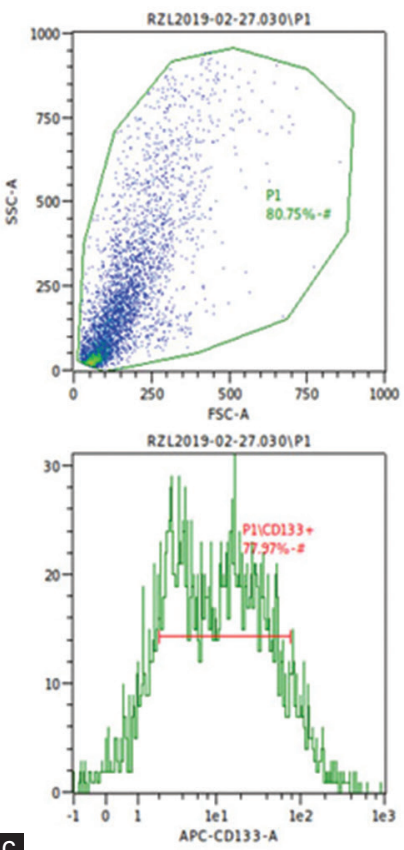
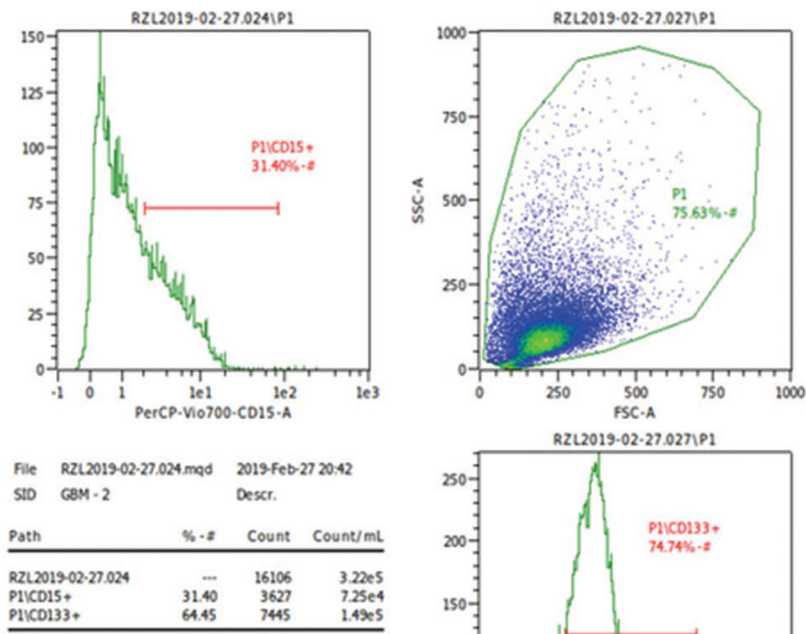

Isolated Primary HGG
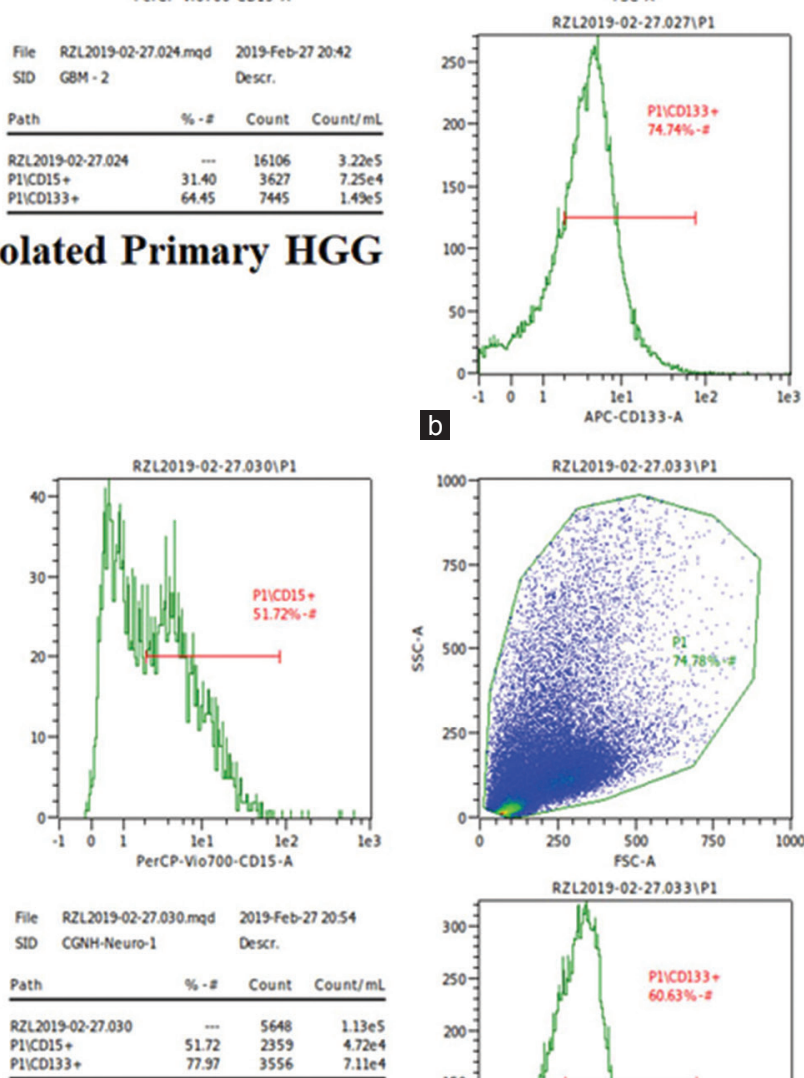

\section{CGNH89 Neurospheres}

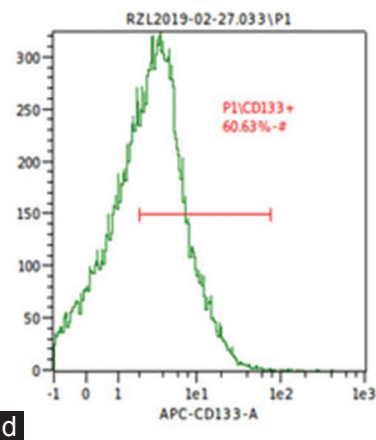

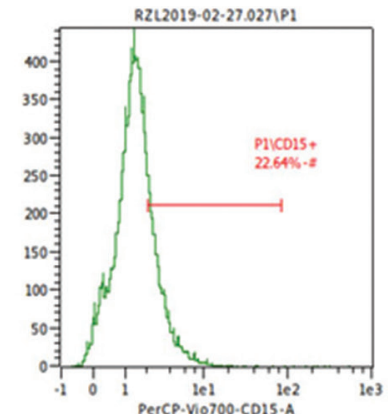

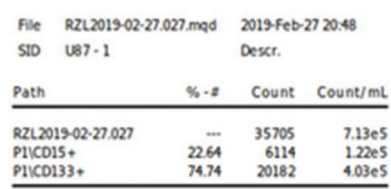

U87 MG Cell Line
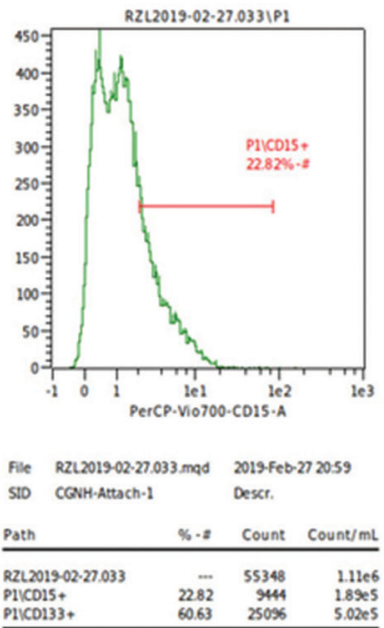

CGNH89 Adherent

Figure 3: Density plot of cluster of differentiation (CD)133 and CD15 in isolated primary glioblastoma (a), U87MG (b), adherent CGNH-89 (c), and spheres CGNH-89 (d)

human HGG cells and comparative cells. Both cells

(Figure 4). The data showed that the main subpopulation coexpress CD133 and CD15 in different proportion in isolated HGG and sphere $\mathrm{CGNH}$ is $\mathrm{CD} 133^{+} / \mathrm{CD} 15^{+}$ 
where the highest subpopulation in U87MG cells is

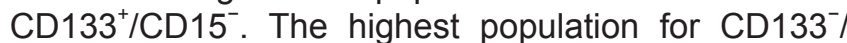
CD15 shown in Figure 5.

\section{Discussion}

Immunostaining of glioma tissue showed the protein expression of GFAP, Ki-67, IDH-1 R132H mutant, and PD-L1. GFAP immunoreactivity indicates that the tumor is astroglial lineage [14]. GFAP is absent in the primitive neuroepithelial cells, oligodendrocytes, ganglion cells, vascular endothelium, meningeal cells, fibroblasts, and other mesenchymal elements [14]. $\mathrm{Ki}-67$ was expressed in $>10 \%$ cells and confirmed the proliferation activity of isolated tumor cells since Ki-67 is an important marker for cell proliferation in clinical practice [12]. Expression of $\mathrm{IDH}-1 \mathrm{R} 132 \mathrm{H}$ mutant suggests that the tumors are likely secondary tumors [15]. The expression of PD-L1 is tightly related to the pathological grade of glioma. This protein will bind to PD-1 protein on B-cells, T-cells, natural killer T-cell, and dendritic cells and is responsible to immune suppression process. The highly expression of PD-L1 in the tumor sections confirmed the high grade of isolated tumor [13].

CD15, known as SSEA-1, expressed as a trisaccharide 3-fucosyl- $\mathrm{N}$-acetyllactosamine, is highly expressed in many types of NSCs in the adult brain [7]. CD15 was proposed to be a marker of tumor-initiating cells (TIC) in human glioblastoma. The use of CD15 as the marker for TIC because it fulfills the functional criteria such as being highly tumorigenic in vivo can give rise to both CD15+ and CD15- cells, thereby establishing a cellular hierarchy and has self-renewal and multilineage differentiation potentials [16]. This study showed that isolated HGG and its comparative

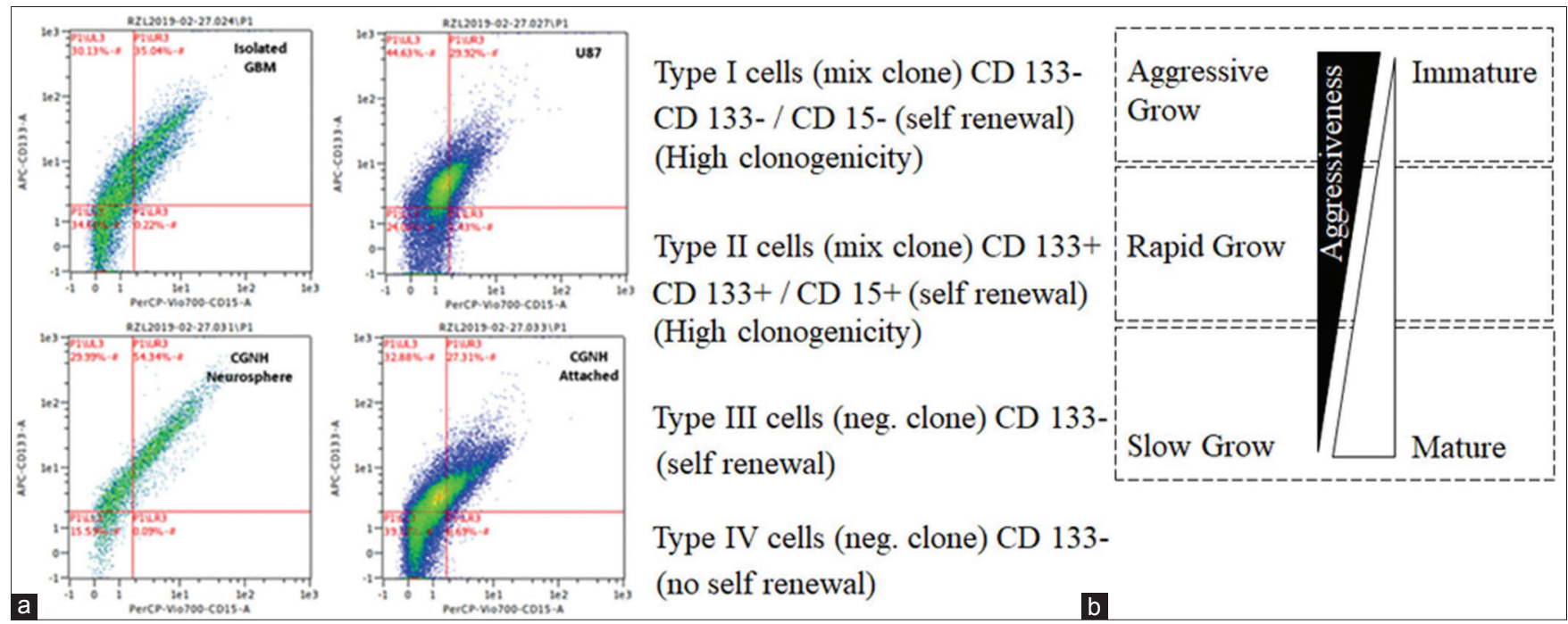

Figure 4: Analysis of isolated primary glioblastoma and comparative cell line by coexpression of cluster of differentiation (CD) $133 / C D 15$ (a). Schematic lineage model of Type I, II, and III cells (comprising CD133- and CD133+) in glioblastoma applying with coexpression of CD133 and CD15 to define distinct intratumoral subpopulations (b) [10], [20]

\begin{tabular}{|c|c|c|c|c|}
\hline \multirow[b]{3}{*}{ U87 Cell Line } & \multicolumn{2}{|c|}{ CD133-/CD15+ CD133+/CD15 } & $\mathrm{CD} 133+/ \mathrm{CD} 15-$ & CD133-/CD15- \\
\hline & & & Type II Cells & Type I Cells \\
\hline & $1,27 \%$ & $45,88 \%$ & $30,05 \%$ & $22,80 \%$ \\
\hline CGNH89 (adherent) & $0,75 \%$ & $35,43 \%$ & $26,20 \%$ & $37,62 \%$ \\
\hline CGNH89 (spheres) & $0,15 \%$ & $29,92 \%$ & $54,56 \%$ & $15,37 \%$ \\
\hline Isolated primary HGG & $0,31 \%$ & $29,37 \%$ & $37,27 \%$ & $33,05 \%$ \\
\hline
\end{tabular}

Figure 5: Subpopulations from lineage model of Type I, II, and III cells (comprising cluster of differentiation [CD] 133- and CD133+) in isolated primary glioblastoma cells and standard cell line by applying double staining of cluster of differentiation (CD) 133 and CD15 (see detail in text) 
cells express CD15. The highest expression of CD15 was in CGNH neurosphere, $51.17 \pm 0.54$. This result indicates that neurosphere expresses more CD15 and CD133 than adherent cells. Ahmed et al. stated that CD133- population are adherent cells [16].

Flow cytometry analysis showed the expression of NSCs marker, CD133. Besides, being a marker for NSCs, CD133 is also a marker for endothelial progenitor cells and hematopoietic stem cells [10], [17]. The proportion of $\mathrm{CD}_{133^{+}}$is $65.73 \pm 1.12 \%$ in isolated HGG. In CGNH-89 cell, we cultured CGNH-89 in two different condition, adherent and spheres culture. The results showed that sphere $\mathrm{CGNH}$ had high $\mathrm{CD} 133^{+}$ expression $(77.69 \pm 0.44$ for sphere $\mathrm{CGNH}$ and 62.52 \pm 1.71 for adherent $\mathrm{CGNH}$ ). $\mathrm{CD}_{133^{+}}$has capability for unlimited self-renewal and has good ability to initiate and drive brain tumor in vivo [9] and CD133 positivity also has high correlation with survival and chemoresistance in gliomas [18]. However, one study also found that there are CD133-negative (CD133-) CSCs in gliomas

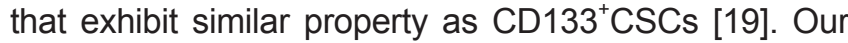
findings also confirmed successful CD133 ${ }^{+}$isolation from secondary glioma since Ahmed et al. reported unsuccessful isolation from secondary glioma and stated that there are no CSCs from secondary glioma [16].

Double staining of CD133 and CD15 defined four different cell subpopulations in isolated glioma and its comparative cells. The result of this study is in agreement with the study that conducted by Kahlert et al. (2012) that separated three different subpopulations,

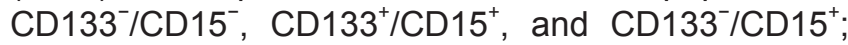
concluding that all subpopulations of the cells had the ability to form neurospheres, with $C D 133^{-} / C D 15^{+}$has lower clonogenicity [10]. These findings correspond to CSCs lineage hierarchy proposed by Chen et al. (2010) that postulated tumor stem cells lineage in glioblastoma. Type I cells (CD133) are able to give rise to aggressive tumors that consist both of $\mathrm{CD} 133^{+}$and $\mathrm{CD} 133^{-}$cells; the Type II cells are positive for CD133 and generate rapidly growing, invasive grafts that comprise also a mixture of $\mathrm{CD}_{133^{+}}$and CD133- cells; and Type III cells (CD133-) form confined slowly growing tumor masses [20]. In addition, the existence of a fourth more differentiated $\mathrm{CD}^{133^{-}}$cell population with non-tumorigenic properties and limited proliferation capacity under neurosphere conditions was proposed. According to the model, Type I, II, and III cells are lineally related and represent discrete stages of differentiation. Type I cells are the least and type III cells the most differentiated, whereas type II cells represent an intermediate stage, as shown in Figure $4 a$ and $b$.

Our results showed that isolated primary glioblastoma cell line and its comparative cell lines

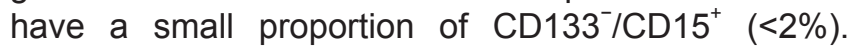
These subpopulations could be categorized as more differentiated population (the fourth type) that has minimal clonogenic potential [10], [20]. The double negative subpopulations $\mathrm{CD} 133^{-} / \mathrm{CD} 15^{-}$are categorized as Type I cells since it has self-renewal and strong clonogenicity [10]; it was dominant in adherent CGNH89 (37.62 $\pm 1.72 \%)$. The double-positive CD133 ${ }^{+} /$ CD $15^{+}$could be categorized as Type II cell, since it has a good renewal capacity; its dominant in spheres CGNH$89(54.56 \pm 0.41 \%)$ and isolated primary glioblastoma cells $(37.27 \pm 1.97 \%)$. It can be concluded that we confirmed the presence of Type I cells, Type II cells, and more differentiated population based on Chen et al. classification [20]. Somehow, we observed an additional

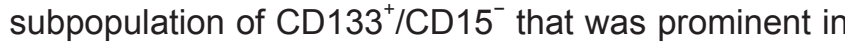
U87MG cells $(45.88 \pm 1.09 \%)$; results summarized in Figure 5 and Table 2.

Double staining of CD133/CD15 can also separate three different subclasses of human glioblastoma cells for their stem cells identity; however, in this study, another subpopulations that have not been reported before $\left(\mathrm{CD} 133^{+} / \mathrm{CD} 15^{-}\right)$need to be added and reclassified in a novel hierarchy [10], [16], [19], [21]. Surprisingly, modification of the cellularmicroenvironment from adherent to become spheres could modify the characteristics of subpopulations, suggesting how important the environment milieu is.

\section{Conclusion}

Our isolated HGG cells could be separated into four different subpopulations by CD133/CD15 double staining. Intratumoral heterogeneity does exist and directly or indirectly depends on their environment. This intratumoral heterogeneity study serves as a foundation for future study in this area and offers insights into the cell type-dependent distribution and disease outcomes.

\section{References}

1. Dolecek TA, Propp JM, Stroup NE, Kruchko C. CBTRUS statistical report: Primary brain and central nervous system tumors diagnosed in the United States in 2005-2009. Neuro Oncol. 2012;14(Suppl 5):v1-49. https://doi.org/10.1093/neuonc/ nos 218

PMid:23095881

2. Alves TR, Lima FR, Kahn SA, Lobo D, Dubois LG, Soletti R, et al. Glioblastoma cells: A heterogeneous and fatal tumor interacting with the parenchyma. Life Sci 2011;89:532-9. https:// doi.org/10.1016/j.Ifs.2011.04.022

PMid:21641917

3. Dirks PB. Brain tumor stem cells: The cancer stem cell hypothesis writ large. Mol Oncol. 2010;4(5):420-30. https://doi. org/10.1016/j.molonc.2010.08.001

PMid:20801091

4. Martin-Hijano L, Sainz B. The interactions between cancer stem cells and the innate interferon signaling pathway. Front Immunol. 2020;11:526. https://doi.org/10.3389/fimmu.2020.00526 


\section{PMid:32296435}

5. Dimov I, Tasić-Dimov D, Conić I, Stefanovic V. Glioblastoma multiforme stem cells. Sci World J. 2011;11:930-58. https://doi. org/10.1100/tsw.2011.42

6. Jin X, Jin X, Jung JE, Beck S, Kim H. Cell surface Nestin is a biomarker for glioma stem cells. Biochem Biophys Res Commun 2013;433(4):496-501. https://doi.org/10.1016/j. bbrc.2013.03.021

PMid:23524267

7. Sundar SJ, Hsieh JK, Manjila S, Lathia JD, Sloan A. The role of cancer stem cells in glioblastoma. Neurosurg Focus. 2014;37(6):E6. https://doi.org/10.3171/2014.9.focus14494 PMid:25434391

8. Faried A, Arifin MZ, Ishiuchi S, Kuwano H, Yazawa S. Enhanced expression of proapoptotic and autophagic proteins involved in the cell death of glioblastoma multiforme induced by synthetic glycans. J Neurosurg. 2014;120(6):1298-308. https://doi. org/10.3171/2014.1.jns131534

PMid:24678780

9. Widowati W, Heriady $\mathrm{Y}$, Laksmitawati DR, Jasaputra DK, Wargasetia TL, Rizal R, et al. Isolation, characterization and proliferation of cancer cells from breast cancer patients. Acta Inform Med. 2019;26(4):228-32. https://doi.org/10.5455/ aim.2018.26.240-244

10. Kahlert UD, Bender NO, Maciaczyk D, Bogiel T, Bar EE, Eberhart CG, et al. CD133/CD15 defines distinct cell subpopulations with differential in vitro clonogenic activity and stem cell-related gene expression profile in in vitro propagated glioblastoma multiforme-derived cell line with a PNET-like component. Folia Neuropathol. 2012;50(4):357-68. https://doi. org/10.5114/fn.2012.32365

PMid:23319191

11. Pavon LF, Marti LC, Sibov TT, Miyaki LA, Malheiros SM, Mamani JB, et al. Isolation, cultivation and characterization of $\mathrm{CD}_{133}+$ stem cells from human glioblastoma. Einstein (Sao Paulo). 2012;10(2):197-202. https://doi.org/10.1590/ s1679-45082012000200013

PMid:23052455

12. Zeng A, Hu Q, Liu Y, Wang Z, Cui X, Li R, et al. IDH1/2 mutation status combined with Ki-67 labeling index defines distinct prognostic groups in glioma. Oncotarget. 2015;6(30):30232-8. https://doi.org/10.18632/oncotarget.4920

PMid:26338964

13. Chen $R Q$, Liu F, Qiu $X Y$, Chen $X Q$. The prognostic and therapeutic value of PD-L1 in glioma. Front Pharmacol. 2019;9:1503

PMid:30687086

14. Goyal R, Mathur SK, Gupta S, Goyal R, Kumar S, Batra A, et al. Immunohistochemical expression of glial fibrillary acidic protein and CAM5.2 in glial tumors and their role in differentiating glial tumors from metastatic tumors of central nervous system. J Neurosci Rural Pract. 2015;6:499-503. https://doi. org/10.4103/0976-3147.168426

PMid:26752892

15. Veganzones $\mathrm{S}$, de la Orden V, Requejo L, Mediero B González ML, del Prado N, et al. Genetic alterations of IDH1 and VEGF in brain tumors. Brain Behav. 2017;7(9):e00718. https://doi.org/10.1002/brb3.718 PMid:28948065

16. Ahmed SI, Javed G, Laghari AA, Bareeqa SB, Farrukh S, Zahid $S$, et al. $C D_{133}$ Expression in glioblastoma multiforme: A literature review. Cureus. 2018;10(10):e3439. https://doi. org/10.7759/cureus.3439

PMid:30555755

17. Brown DV, Filiz G, Daniel PM, Hollande F, Dworkin S, Amiridis S et al. Expression of CD133 and CD44 in glioblastoma stem cells correlates with cell proliferation, phenotype stability and intratumor heterogeneity. PLoS One. 2017;12(2):e0172791. https:// doi.org/10.1371/journal.pone.0172791 PMid:28241049

18. Wu X, Wu F, Xu D, Zhang T. Prognostic significance of stem cell marker $C_{133}$ determined by promoter methylation but not by immunohistochemical expression in malignant gliomas. J Neurooncol. 2016;127(2):221-32. https://doi.org/10.1007/ s11060-015-2039-z PMid:26757925

19. Brescia P, Richichi C, Pelicci G. Current strategies for identification of glioma stem cells: Adequate or unsatisfactory? J Oncol 2012;2012:376894. https://doi.org/10.1155/2012/376894 PMid:22685459

20. Chen R, Nishimura MC, Bumbaca SM, Kharbanda S, Forrest WF Kasman IM, et al. A hierarchy of self-renewing tumor-initiating cell types in glioblastoma. Cancer Cell. 2010;17(4):362-75. https://doi.org/10.1016/j.ccr.2009.12.049 PMid:20385361

21. Ludwig K, Kornblum HI. Molecular markers in glioma. J Neurooncol. 2017;134(3):505-12.

PMid:28233083 